\title{
An Improved Surgical Technique for Pure Laparoscopic Left Hemihepatectomy: Ten Years Experience in a Tertiary Center
}

\author{
Xuefei Wang, MD,,2 Minggen Hu, MD,' Zhiming Zhao, MD, Chenggang Li, MD, Guodong Zhao, MD, \\ Yong $\mathrm{Xu}, \mathrm{MD}, 1$ Dabin $\mathrm{Xu}, \mathrm{MM},{ }^{1}$ and Rong Liu, MD ${ }^{1}$
}

\begin{abstract}
Background: This study details our experience with an improved surgical technique involving the hepatic pedicle during laparoscopic left hemihepatectomy (LLH).

Methods: We describe an improved laparoscopic technique to extraparenchymally divide the left hepatic pedicle. A retrospective analysis of all of the patients who underwent laparoscopic liver procedures between 2002 and 2012 was conducted. The patients were divided into two groups, an early LLH group (ELLH group) and a recent LLH group (RLLH group), based on the surgical approach used for the left hepatic pedicle.

Results: A total of 72 cases of LLH (26 ELLH and 46 RLLH) were identified. The RLLH group exhibited a shorter median operative time, median length of hospital stay, and lower median blood loss compared to the ELLH group $(182,162.5-223.7$ versus $232.5,200-357.5$ minutes, $P<.01 ; 5,4.2-7$ versus $7,6-8.7$ days, $P<.05 ; 150$, $100-257.5$ versus $300,200-337.5 \mathrm{~mL}, P<.05$, respectively). No perioperative mortality was observed.

Conclusions: This study confirms that our improved surgical technique for LLH is practical, safe, and effective. The main advantage of this method compared to other techniques is the possibility of attaining rapid and precise control of vascular inflow, thus facilitating LLH.
\end{abstract}

Keywords: laparoscopic liver resection, hemihepatectomy, hepatic pedicle, minimally invasive surgery, major liver resection, oncological surgery

\section{Introduction}

$\mathbf{M}$ INIMALLY INVASIVE SURGERY has gained worldwide acceptance and has changed modern surgery practices. As an important part of minimally invasive surgery, laparoscopic surgery has been widely used in gynecology and urology; furthermore, various fields recognize this technique as the standard surgical approach. ${ }^{1-3}$ However, the development of laparoscopic liver surgery was delayed due to concerns regarding potential difficulties in controlling bleeding, inadequate surgical margins, and port-site tumor cell implantation.

Over the past decade, reports from numerous centers have demonstrated that laparoscopic resection in selected patients is feasible, safe, and effective with satisfactory operative and oncologic results. ${ }^{4-7}$ Many studies have reported the superi- ority of laparoscopic minor liver resection compared with open procedures for peripheral lesions or lesions located in segments II and III. Laparoscopic left lateral sectionectomy is considered a standard surgical procedure for benign and malignant liver diseases. ${ }^{8-10}$ Currently, laparoscopic left hemihepatectomy (LLH) is perceived as a complex procedure, and it is only performed in a limited number of cases by experienced laparoscopic surgeons. ${ }^{7}$

Since the first laparoscopic liver resection was completed in 2002, 72 patients have undergone pure LLH. In this study, we describe our experience with a safe, feasible laparoscopic technique that addresses the challenges associated with dissection of the left hepatic pedicle. This modified procedure has been successfully performed in 46 patients since 2007.

\footnotetext{
${ }^{1}$ Department of Hepatobiliary and Pancreatic Surgical Oncology, Chinese People's Liberation Army (PLA) General Hospital, Beijing, China.

${ }^{2}$ Emergency Department, Chinese PLA Navy General Hospital, Beijing, China.

(C) Xuefei Wang et al. 2016; Published by Mary Ann Liebert, Inc. This Open Access article is distributed under the terms of the Creative Commons Attribution Noncommercial License (http://creativecommons.org/licenses/by-nc/4.0/) which permits any noncommercial use, distribution, and reproduction in any medium, provided the original author(s) and the source are credited.
} 


\section{Materials and Methods}

\section{Patient selection}

We retrospectively reviewed a prospective database of all patients who underwent laparoscopic liver surgery for either benign or malignant liver disease performed by our team between 2002 and 2012. Patients were divided into two groups, an early LLH group (ELLH group) and a recent LLH group (RLLH group), based on the different surgical approach used for the left hepatic pedicle. All patients received a preoperative systemic assessment that included a blood test, electrocardiography or echocardiography examination, and chest radiographic examination or pulmonary function test. Imaging assessments, including abdominal ultrasound or contrast-enhanced ultrasonography, contrast-enhanced computed tomography, and/or magnetic resonance imaging, were used to aid in the location of liver lesions and intrahepatic vascular structures and their positional relationship.

Patient selection was based on the following inclusion criteria: small lesions (generally less than $10 \mathrm{~cm}$ ) of exophytic or subcapsular tumors that were localized in the left liver without major vascular invasion and well beyond the transection line to ensure an adequate surgical margin (more than $3 \mathrm{~cm}$ away from the middle hepatic vein), wellcompensated cirrhosis of the liver without signs of severe portal hypertension (esophageal varices grade 1), a platelet count of at least $80 \times 10^{9} / \mathrm{L}$, and an American Society of Anesthesiologists score (ASA) of less than 4. Patients with lesions adjacent to the hepatic hilum or a resection margin were not suitable for a laparoscopic approach due to the risk of bleeding and compromise of oncologic outcomes.

Intraoperative and postoperative variables, such as operative time, blood loss, transfusion requirements, conversion to open procedure, surgical margin, pathology, complications, and length of postoperative hospital stay, were recorded and analyzed. Liver resections were defined according to the Brisbane 2000 Nomenclature of Liver Anatomy and Resections. Postoperative complications were classified according to Clavien-Dindo methodology.

\section{Surgical technique}

The patient is placed in the supine position or adjusted properly to an elevated dorsal position to improve the convenience of the dissection and mobilization of the left liver. The primary surgeon and second assistant stand on the right side of the patient, and the first assistant stands on the left side. A continuous pneumoperitoneum of $\mathrm{CO}_{2}$ is established with the assistance of a Veress needle at a pressure of $12 \mathrm{mmHg}$ to reduce the risk of gas embolism.

A 12-mm trocar is placed at the upper umbilical region for the $30^{\circ}$ laparoscope. After a preliminary abdominal cavity exploration, one 12-mm trocar is positioned in the region $4 \mathrm{~cm}$ inferior to the intersection of the right midclavicular line and subcostal margin line and another $12-\mathrm{mm}$ trocar is positioned $2 \mathrm{~cm}$ inferior to the intersection of the left midclavicular line and subcostal margin line. Using these two trocars, the surgeon can easily change the instruments, as necessary, to perform the dissection of the left hepatic pedicle and transection of the liver parenchyma with both right and left hands. A 5-mm trocar is positioned at the left anterior axillary line $2 \mathrm{~cm}$ superior to the umbilical horizontal plane to enable the first assistant to perform traction, exposure, and suction (Fig. 1).

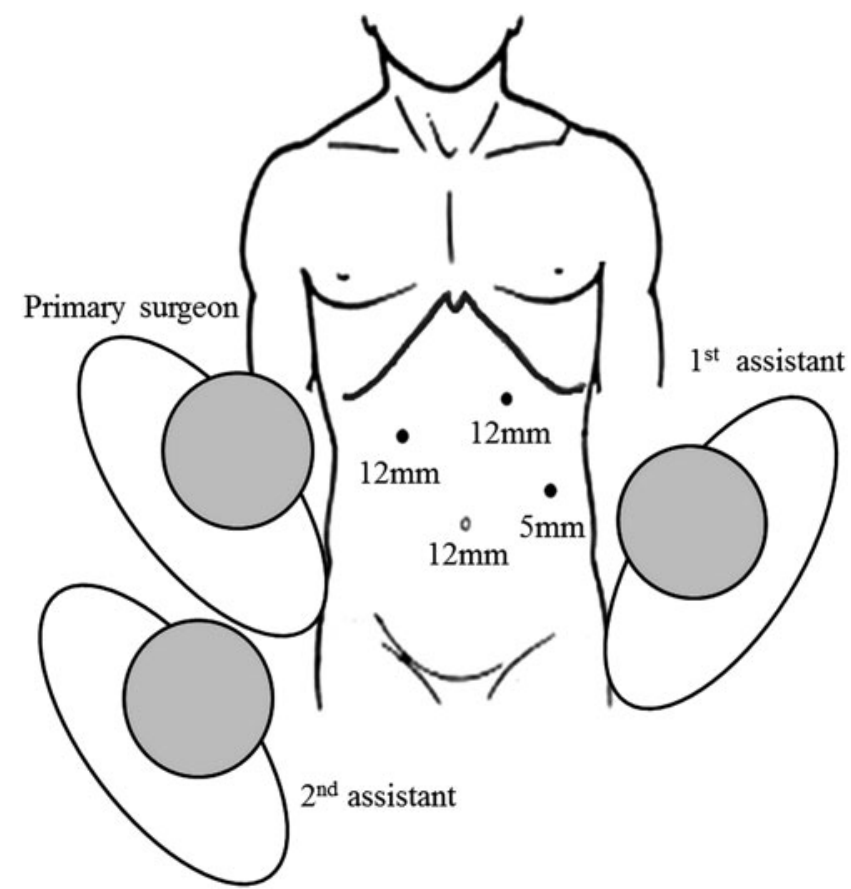

FIG. 1. Trocar placement during left hemihepatectomy.

The location of the trocar can be adjusted based on examination of the abdominal cavity to allow for improved use of the laparoscopic surgical tools and facilitate the introduction of the endoscopic linear cutting stapler immediately in front of the section line.

Laparoscopic examination combined with preoperative imaging is required to determine the location and extent of the hepatic lesion, identify the anatomical relationship between the lesion and intrahepatic vascular system, and confirm the possibility of an R0 resection. Laparoscopic ultrasonography (Aloka Prosound $\alpha 5$; Mitaka-Shi, Tokyo, Japan; 4-10 MHz laparoscopic transducer) excludes other possible lesions and detects the ramus communicans of the middle hepatic vein. Multiple ligaments are transected with a harmonic scalpel (UltraCision; Ethicon Endosurgery, Cincinnati, $\mathrm{OH}$ ) and diathermy hook, including the round ligament, falciform ligament, hepatogastric ligament, left triangular ligament, and coronary ligaments. In some cases, the right coronary ligament adjacent to the second hepatic portal is partially transected to mobilize the entire left liver and facilitate parenchymal transection.

The left hepatic pedicle is dissected extraparenchymally with a conventional hilar dissection approach in the ELLH group, but with an improved intra-Glissonian approach in the RLLH group. Transection of the left hepatic artery uses the same step in both groups during dissection of the left hepatic pedicle. The peritoneum on the left side of the hepatoduodenal ligament is incised with a harmonic scalpel. The left hepatic artery is first dissected using a diathermy hook to separate the surrounding lymphatic connective tissues. Next, $30^{\circ}$ curved laparoscopic dissecting forceps are passed around the vascular structure (Fig. 2A). Fine anatomical dissection adjacent to the vascular structure is performed bluntly without electrosurgical tools. The left hepatic artery is clipped with an absorbable ligating clip (Lapro-Clip; Covidien, North Haven, CT) and closely divided near the liver (Fig. 2B). 

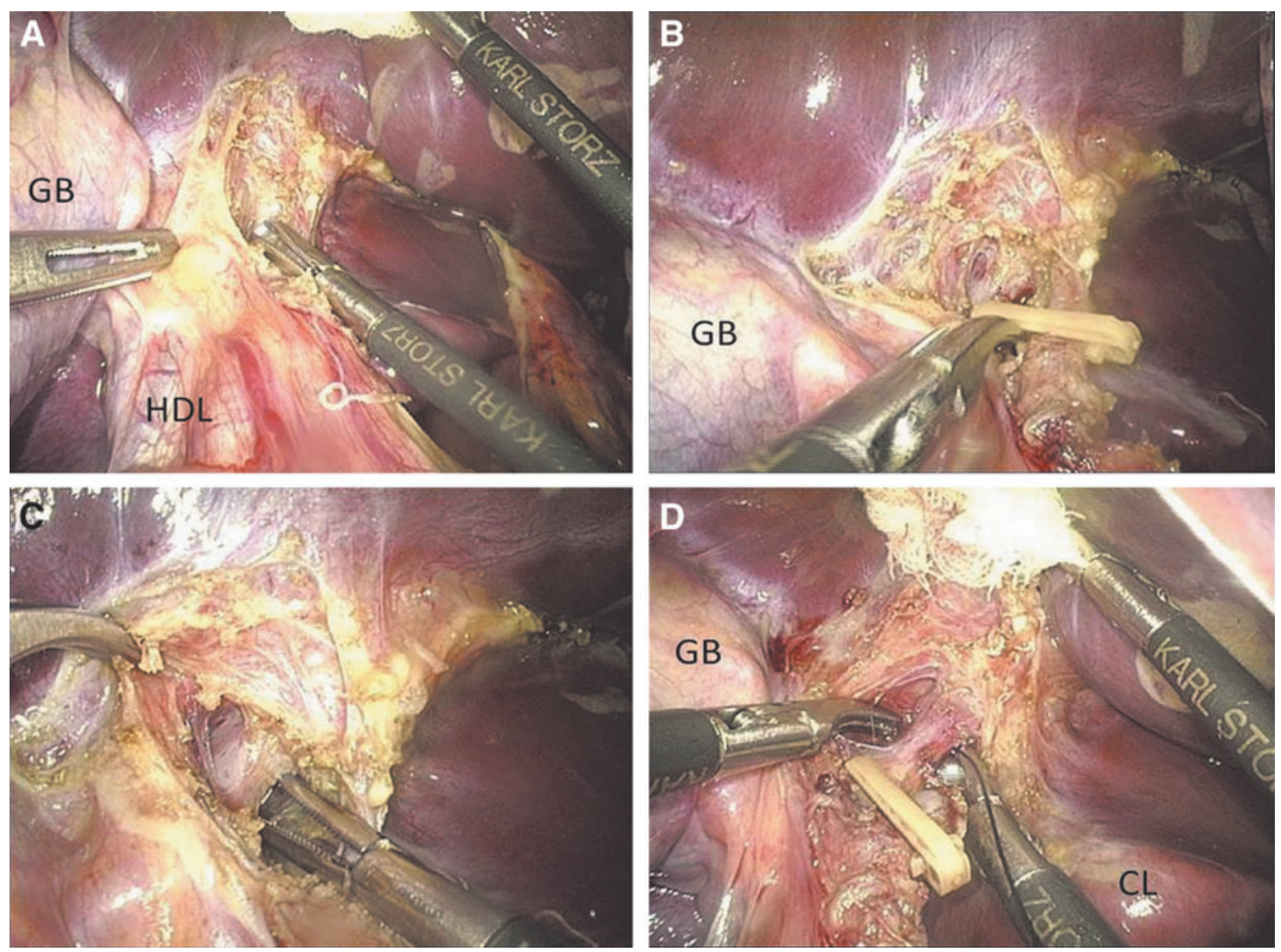

FIG. 2. (A) Dissection of the left hepatic pedicle. (B) The left hepatic artery was clipped with a Lapro-Clip. (C) Dissection of the left branch portal. (D) The left branch portal is isolated and ligated with 4-0 silk sutures. CL, caudate lobe; GB, gallbladder; HDL, hepatoduodenal ligament.

The main differences in the surgical approach between the two groups concern the treatments of the left hepatic vein and left bile duct, after the transection of the left hepatic artery. In the ELLH group, the left branch portal vein and left bile duct are divided, clipped, and transected successively in the same way as the left hepatic artery. However, in the RLLH group, only the left branch portal vein is divided and ligated with 4-0 silk sutures instead of flinty clips (Fig. 2C, D); then, the dissection of the left hepatic pedicle is performed. The transection of the left branch portal vein and dissection of the left bile duct are not required. Using either the conventional or improved technique, the left branch portal vein needs to be carefully dissected until the portal bifurcation is identified and the branches of the caudate lobe should be preserved.

The vascular outflow of the left liver is not routinely controlled before transection of the liver parenchyma. The left coronary ligament and a portion of the right coronary ligament are transected for adequate visualization of the left hepatic vein and optimal mobilization of the left liver. Extraparenchymal dissection of the left hepatic vein is performed up to the level of the insertion into the inferior vena cava to confirm the existence of the common trunk with the middle hepatic vein (Fig. 3A). This procedure facilitates secure intraparenchymal stapling of the left hepatic vein once the parenchymal dissection is almost complete. Accidental injury of the left inferior phrenic vein, which may cause postoperative hemorrhage, should be detected intraoperatively and be reliably controlled through the application of Lapro-Clips (Fig. 3B).
A liver parenchymal transection is performed after control of the vascular inflow, dissection of the left hepatic vein, and mobilization of the left liver. An ischemic penumbral change of the left liver after control of the vascular inflow indicates the range of parenchymal resection. The choice of devices for parenchymal transection varies according to the surgeon's experience and preference. In this study, the combination of a harmonic scalpel and bipolar coagulation (BiClamp LAP forceps; ERBE Elektromedizin $\mathrm{GmbH}$, Tubingen, Germany) provides rapid and efficient transection. Liver incision from the liver capsule to $2 \mathrm{~cm}$ deep into the parenchyma is easily achieved through the use of a harmonic scalpel. When liver transection is continued deeper into the parenchyma, the division of pipeline structures larger than $3 \mathrm{~mm}$ diameter is achieved using Lapro-Clips.

The left liver is gently pulled out or elevated to achieve an adequate space and clear visualization, facilitating the insertion of the endoscopic linear cutting stapler along the transection line. The left hepatic pedicle is divided after confirmation that it is entirely encompassed by an Echelon 60 (Fig. 3C). In a similar manner, the left hepatic vein is transected during the transection of the residual posterior liver parenchyma (Fig. 3D).

The raw surface of the liver parenchyma is examined carefully for bleeding and bile leaks. Small bleeding points are reliably controlled with Argon plasma coagulation (APC 300; ERBE Elektromedizin $\mathrm{GmbH}$ ) or a BiClamp. The valve of the trocar is opened to stabilize the pneumoperitoneum pressure at $12 \mathrm{mmHg}$ while using Argon plasma coagulation. 

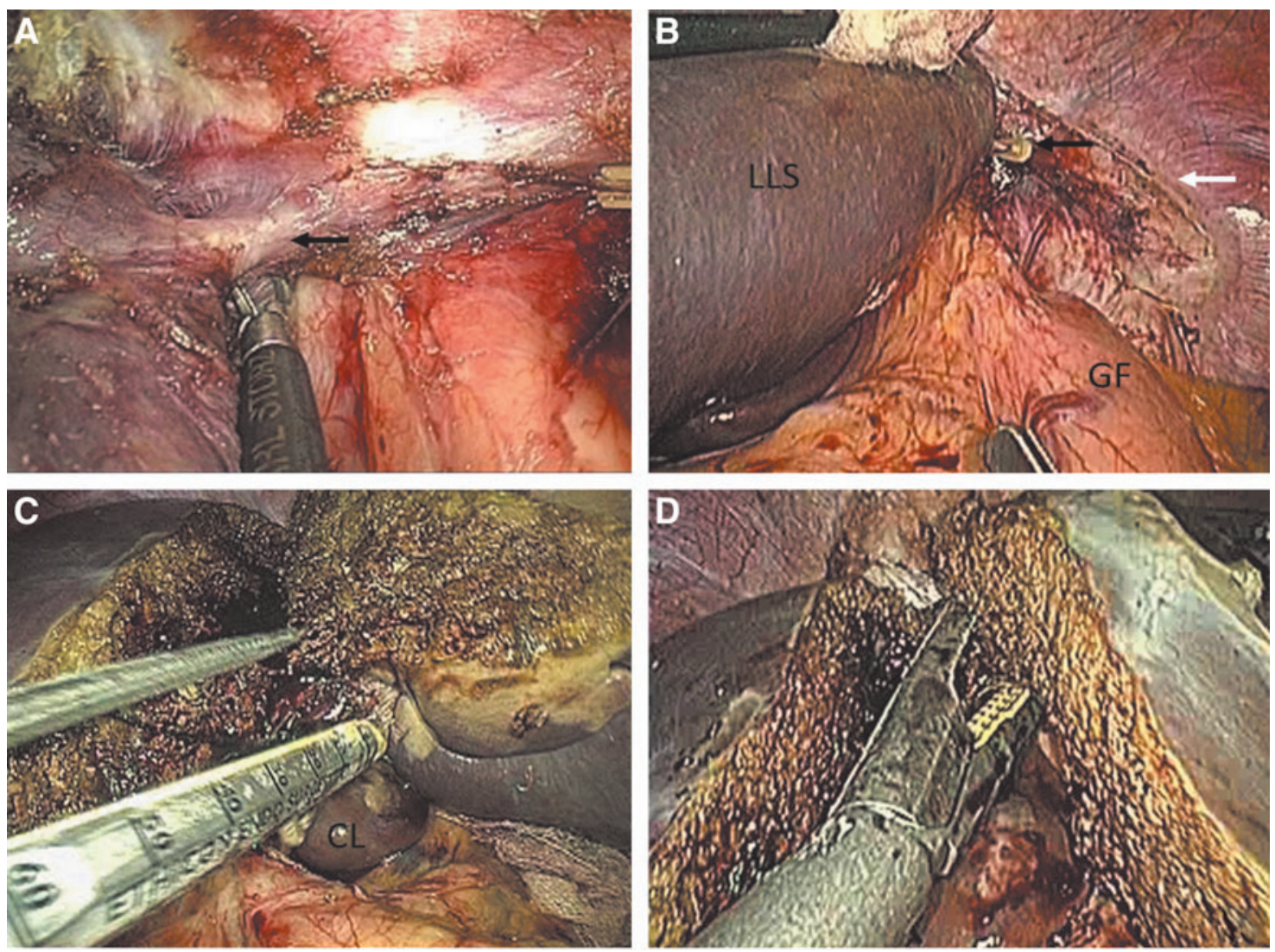

FIG. 3. (A) Dissection of the left hepatic vein. The black arrow indicates the location where the left hepatic vein drains into the inferior vena cava. (B) The black arrow indicates the inferior phrenic vein clipped with a Lapro-Clip. The white arrow indicates the left coronary and triangular ligaments that have been transected. (C) Intraparenchymal transection of the left hepatic pedicle with an endoscopic linear cutting stapler. (D) The left hepatic vein is transected with an endoscopic linear cutting stapler once transection of the liver parenchyma is almost complete. CL, caudate lobe; GF, gastric fundus; LLS, left lateral section.

Lapro-Clips and PROLENE sutures are used to obtain exact hemostasis for any substantive bleeding. The specimen is placed in a disposable bag (EndoCATH; Ethicon EndoSurgery, North Haven, CT) and removed by an extended incision of the left subcostal port. Abdominal drainage is routinely placed near the site of transection.

\section{Statistical analysis}

Continuous clinicopathological variables with a normal distribution are expressed as the mean \pm standard deviation. Variables that did not demonstrate a normal distribution are expressed as medians (interquartile range). Categorical variables are reported as numbers and percentages (\%). Differences in the means and medians between two groups were compared using Student's $t$-test or the Wilcoxon rank-sum test. Comparisons of categorical variables were performed using a chi-square test or Fisher's exact test. $P$ values less than .05 were considered statistically significant.

\section{Results}

A total of 72 patients underwent a pure LLH between January 2002 and December 2012. In the ELLH group, 26 patients, including 19 men and 7 women, with an average age of $45.4 \pm 5.9$ years, have undergone LLH using the conventional hilar dissection technique. With this technique, the left hepatic artery, left branch portal, and left hepatic duct are successively dissected, obstructed by absorbable clips, and transected extraparenchymally.

In the RLLH group, 46 patients, including 28 men and 18 women, with an average age of $41.9 \pm 16.5$ years, have undergone LLH using the improved technique for dissection of the left hepatic pedicle. With this improved technique, the left hepatic artery is treated in a similar way to the conventional hilar dissection technique, the left branch portal vein is ligated using 4-0 silk sutures instead of hard clips after dissection but not transected, and the extraparenchymal dissection of the left hepatic duct is abandoned.

The detailed characteristics of patients are summarized in Table 1. In total, $22(47.8 \%)$ and $6(23.7 \%)$ patients in the RLLH and ELLH groups, respectively, were seropositive for the hepatitis B virus surface antigen (HBsAg). The surgical outcome details are summarized in Tables 2 and 3. In the RLLH group, the operative time was significantly shorter (182, 162.5-223.7 versus 232.5, 200-357.5 minutes; $P<.01)$ and blood loss was decreased $(150,100-257.5$ versus $300,200-337.5 \mathrm{~mL} ; P<.05)$, compared with the ELLH group. No significant differences in the transfusion and conversion rates were observed between the two groups. As described in Table 3, the postoperative hospital duration was shorter in the RLLH group $(5,4.2-7$ versus 7 , $6-8.7$ days; $P<.05)$. No differences in the length of postoperative ambulation and resumption of oral intake were observed. 
Table 1. Demographic and Clinical Characteristics of Patients

\begin{tabular}{lccc}
\hline & $R L L H(\mathrm{n}=46)$ & $E L L H(\mathrm{n}=26)$ & $\mathrm{P}$ value \\
\hline Sex (female/male) & $18 / 28$ & $7 / 19$ & .30 \\
Age (years) & $41.9 \pm 16.5$ & $45.4 \pm 5.9$ & .30 \\
BMI (kg/m $\left.{ }^{2}\right)$ & $22.6 \pm 6.8$ & $26.3 \pm 7.5$ & .04 \\
HBSAg+ (\%) & $22(47.8 \%)$ & $6(23.7 \%)$ & .04 \\
ASA status (\%) & & & \\
$\quad$ I-II & $40(87.0 \%)$ & $26(100 \%)$ & .14 \\
III & $6(13.0 \%)$ & 0 & \\
Child-Pugh (\%) & & & \\
$\quad$ A & $43(93.5 \%)$ & $25(96.2 \%)$ & .10 \\
B & $3(6.5 \%)$ & $1(3.8 \%)$ & \\
\hline
\end{tabular}

ASA, American Society of Anesthesiologists score; BMI, body mass index; ELLH, early laparoscopic left hemihepatectomy; $\mathrm{HBsAg}$, hepatitis B virus surface antigen; RLLH, recent laparoscopic left hemihepatectomy.

The complication rate was lower in the RLLH group; however, the difference did not achieve statistical significance (8.7\% versus $15.3 \%, P=.6333$ ). Four complications were observed in 4 patients from the RLLH group, including hemorrhage, bile leak, ascites, and a pulmonary complication. The severity of complications in both groups was below grade II according to Clavien's classification. The pathological results are outlined in Table 4. In the RLLH group, $60.8 \%$ of the resections were performed for malignant disease, a value that was increased compared with the ELLH group $(60.8 \%$ versus $34.6 \%$, respectively; $P=.0323)$. All resections for malignant lesions acquired sufficient surgical margins in both groups with no significant differences.

Comparison of the two groups revealed that the improved technique was associated with reduced operative time, less intraoperative blood loss, fewer complications, and a shorter postoperative hospital stay. As presented in Table 5, we experienced a similar median length of hospital stay, conversion, and transfusion rate, while the median operative time, blood loss, and complication rate in this series are comparable with recently published results.

\section{Discussion}

The advantages of laparoscopic liver resection compared with conventional open surgery, including reduced postoperative pain, less operative blood loss, enhanced cosmetic outcome, shorter hospital stay, a comparable complication

Table 2. Intraoperative Outcomes

\begin{tabular}{lccc}
\hline & $R L L H(\mathrm{n}=46)$ & ELLH $(\mathrm{n}=26)$ & $\mathrm{P}$ value \\
\hline $\begin{array}{l}\text { Operative time } \\
\quad \text { (minutes) }\end{array}$ & $182(162.5-223.7)$ & $232.5(200-357.5)$ & $<.01$ \\
$\begin{array}{l}\text { Estimated blood } \\
\quad \text { loss (mL) }\end{array}$ & & & \\
Transfusion (\%) & $150-257.5)$ & $300(200-337.5)$ & $<.05$ \\
PRBC (unit) & 6 & $1(3.8 \%)$ & .74 \\
FFP (unit) & 2.3 & 3 & \\
Conversion (\%) & $1(2.2 \%)$ & $1(3.8 \%)$ & .74 \\
\hline
\end{tabular}

ELLH, early laparoscopic left hemihepatectomy; FFP, fresh frozen plasma; PRBC, packed red blood cell; RLLH, recent laparoscopic left hemihepatectomy.
Table 3. Postoperative Outcomes

\begin{tabular}{lccc}
\hline & RLLH $(\mathrm{n}=46)$ & ELLH $(\mathrm{n}=26)$ & $\mathrm{P}$ value \\
\hline LOS (days) & $5(4.2-7)$ & $7(6-8.7)$ & $<.05$ \\
Resume oral & $48.6 \pm 14.4$ & $46.7 \pm 15.3$ & .60 \\
$\quad$ intake (hours) & & & \\
Ambulation (hours) & $38.3 \pm 9.5$ & $37.6 \pm 11.9$ & .81 \\
Drainage (days) & $4.3 \pm 2.4$ & $3.3 \pm 1.4$ & .06 \\
Complications (\%) & $4(8.7 \%)$ & $4(15.3 \%)$ & .63 \\
$\quad$ Hemorrhage & 1 & 2 & .61 \\
Bile leaks & 1 & 1 & .74 \\
Ascites & 1 & 1 & .74 \\
Pulmonary & 1 & 0 & .77 \\
\hline
\end{tabular}

ELLH, early laparoscopic left hemihepatectomy; LOS, length of postoperative hospital stay; RLLH, recent laparoscopic left hemihepatectomy.

rate, and cost effectiveness, have been demonstrated in several studies. After an initially slow and cautious development, laparoscopic liver resections have now been performed worldwide.

In many centers, laparoscopic liver resections are the preferred procedure for lesions located peripherally or in the left lateral section. ${ }^{14-17}$ According to a global questionnaire survey of 18 centers, more than 5000 laparoscopic liver resections have been completed, including 1184 laparoscopic major liver resections. Laparoscopic right and left hemihepatectomy accounted for $34.1 \%$ and $34.3 \%$ of all major liver resections, respectively. Laparoscopic hemihepatectomy is still perceived as a complex procedure that should be confined to surgeons with considerable experience in both laparoscopic and open hepatobiliary surgeries. ${ }^{18}$ Despite technical challenges, current multicenter studies indicate its safety and efficacy in selected patients with an acceptable morbidity and mortality compared with open liver resections. ${ }^{19,20}$

Reducing intraoperative blood loss for the purpose of a clearer operative view, lower transfusion, and enhanced patient outcome is a continuing concern in laparoscopic hemihepatectomy. ${ }^{21}$ Decreased intraoperative blood loss is a major advantage of laparoscopic liver resection compared

Table 4. Oncologic Results

\begin{tabular}{lccc}
\hline & $\begin{array}{c}\text { RLLH } \\
(\mathrm{n}=46)\end{array}$ & $\begin{array}{c}\text { ELLH } \\
(\mathrm{n}=26)\end{array}$ & P value \\
\hline Malignant lesions (\%) & $28(60.8 \%)$ & $9(34.6 \%)$ & .03 \\
HCC & $22(47.8 \%)$ & $7(26.9 \%)$ & .08 \\
ICC & $5(10.9 \%)$ & $2(7.6 \%)$ & .66 \\
Colorectal cancer & $1(2.2 \%)$ & 0 & .77 \\
$\quad$ liver metastasis & & & \\
Surgical margin (cm) & $1.8 \pm 1.1$ & $1.6 \pm 0.7$ & .50 \\
Benign lesions (\%) & $18(39.2 \%)$ & $17(65.4 \%)$ & .03 \\
$\quad$ Hepatic hemangioma & $10(21.7 \%)$ & $12(46.1 \%)$ & .03 \\
FNH & $5(10.9 \%)$ & $2(7.6 \%)$ & .98 \\
Hepatolithiasis & $1(2.2 \%)$ & $1(3.8 \%)$ & .74 \\
Angiomyolipoma & $2(4.3 \%)$ & $1(3.8 \%)$ & .61 \\
Hepatic cyst & 0 & $1(3.8 \%)$ & .36 \\
\hline
\end{tabular}

ELLH, early laparoscopic left hemihepatectomy; FNH, focal nodular hyperplasia; HCC, hepatocellular carcinoma; ICC, intrahepatic cholangiocarcinoma; RLLH, recent laparoscopic left hemihepatectomy. 
Table 5. Comparison with Other Recently Published Series

\begin{tabular}{|c|c|c|c|c|}
\hline & Pearce et al. ${ }^{11}$ & Namgoong et al. ${ }^{12}$ & Belli et al. ${ }^{13 \mathrm{a}}$ & Our report \\
\hline Case number & 20 & 37 & 82 & 46 \\
\hline Operative time (min) & $290(140-480)$ & $257 \pm 50.4$ & $234 \pm 138$ & $182(162.5-223.7)$ \\
\hline Estimated blood loss (mL) & $300(50-1500)$ & $280 \pm 96.9$ & $306 \pm 371$ & $150(100-257.5)$ \\
\hline LOS (days) & $4(1-12)$ & $8.8 \pm 4.1$ & $7.1 \pm 5.1$ & $5(4.2-7)$ \\
\hline Conversion $(\%)$ & 0 & 0 & $3(4 \%)$ & $1(1.8 \%)$ \\
\hline Transfusion (\%) & $2(10 \%)$ & 0 & $39(47 \%)$ & $2(3.6 \%)$ \\
\hline Complication (\%) & $3(15 \%)$ & $4(10.8 \%)$ & $16(20 \%)$ & $4(7.2 \%)$ \\
\hline 90-day mortality (\%) & 0 & 0 & $1(1 \%)$ & 0 \\
\hline
\end{tabular}

${ }^{\mathrm{a}}$ This series contains hand-assistance laparoscopic liver resections.

LOS, length of postoperative hospital stay.

with open surgery. ${ }^{7,22}$ By contrast, intraoperative bleeding is a common cause of conversion due to the difficulty in achieving hemostasis laparoscopically during major liver resections. $^{23,24}$ Thus, prior effective control of vascular inflow to reduce intraoperative blood loss is a significant step in left hemihepatectomies.

According to published reports, three laparoscopic techniques have been generally utilized to divide the left pedicle as described below. With a hilar dissection approach, the peritoneal fascia of the left pedicle is incised; the left hepatic artery, left branch portal, and left hepatic duct are successively dissected, obstructed by titanium, absorbable or Hemo-Lok clips, and transected extraparenchymally. ${ }^{11,25,26}$ With an extrahepatic Glissonian approach, the left hepatic pedicle is isolated extraparenchymally and the left portal triad is encircled with a tape and divided en bloc with an endoscopic stapler without incision of the fibrous sheath that envelopes the entire portal triad. ${ }^{27,28}$ With an intrahepatic Glissonian approach, the left portal triad is obstructed by a laparoscopic vascular clamp, which is inserted into the liver parenchyma according to a specific anatomic landmark, and then transected en bloc with a stapler intraparenchymally. ${ }^{29,30}$

Based on a prospective randomized trial that compared hilar dissection with the Glissonian approach for open major liver resection, the intraoperative blood loss, overall operative time, and complications were largely similar; however, the en bloc stapled transection of the pedicle required less time. ${ }^{31}$ During laparoscopic major liver resection using an intrahepatic or extrahepatic Glissonian approach, the left hepatic pedicle is completely divided without a separate dissection of each portal structure. Despite the lack of randomized controlled trials (RCTs) for laparoscopic major liver resection, these techniques are feasible, reduce technical difficulties, provide rapid access to the left pedicle for control of vascular inflow, and expedite the transection of the liver. ${ }^{27-30}$

However, without a direct visualization of each element in the left pedicle, en bloc transection can cause vascular and biliary duct injury if anatomic variations exist. Without confirmation of anatomical distribution, the vascular branches leading to the caudate lobe and bile duct of the caudate lobe or right liver that frequently drains into the left bile duct could be injured. It is difficult to confirm whether the stapler is correctly positioned in the parenchyma based on the discoloration of the left liver. Using this indirect indicator, it is difficult to control the distal end of the stapler jaws to completely encompass the left hepatic pedicle while not stapling the contralateral biliary duct. Therefore, tumors located near the left hepatic pedicle are a contraindication for both the intrahepatic and extrahepatic Glissonian approach, but not the hilar dissection technique.

In addition to the vascular inflow, the left bile duct is dissected and divided extraparenchymally during a conventional hilar dissection. ${ }^{26}$ In our early cases of LLH (ELLH group), each element of the left hepatic pedicle was carefully dissected and transected using this technique. This procedure can be time-consuming and carries the risk of accidental injury to variant bile ducts, such as the bile duct from the right posterior section that drains into the left hepatic duct. The division of the left hepatic artery exposes sufficient space for the division of the left branch portal vein. The left hepatic artery can be reliably clamped by clips depending on the thickness and elasticity of the arterial wall (Fig. 2B). However, this is not similar to the left branch portal when it is separated from the surrounding tissue, clipped, and divided. Given the thin and fragile venous wall, these clips can be dislodged and can slit the portal vein during mobilization of the left liver, dissection of their adjacent tissues, or specimen removal. $^{24}$

With the improved technique described in this article, the extraparenchymal division of the left hepatic duct is abandoned and the left branch portal vein is ligated, but not transected, using 4-0 silk sutures instead of flinty clips after dissection (Fig. 2D). In this improvement, the treatment of the left branch portal vein is optimized and the dissection of the left bile duct is eliminated, allowing for rapid and precise control of vascular inflow, minimizing the aforementioned risks and expediting liver resection. The ligated left branch portal together with the left bile duct is divided intraparenchymally using an endoscopic linear cutter stapler when the parenchyma is transected to their vicinity (Fig. 3C). The median operative time was significantly reduced in the RLLH group compared with patients in the ELLH group, who underwent the conventional technique (Table $2 ; 182$, 162.5-223.7 versus $232.5,200-357.5$ minutes, $P<.01)$.

A common trunk for the left hepatic vein and middle hepatic vein draining into the inferior vena cava is frequently present. In this study, division of the hepatic vein extraparenchymally is not routinely performed because it is timeconsuming and increases the risk for bleeding and a gas embolism. The left hepatic vein is dissected in favor of mobilization of the left liver, facilitating the introduction of the stapler. Similarly, the left hepatic vein is divided after the 
parenchyma transection is nearly complete (Fig. 3D). An appropriate parenchymal thinness and a clear field are essential for a safe and reliable staple.

Like other surgeons at many centers, at the beginning of major laparoscopic liver resection, we were not sure about the oncological efficacy of major laparoscopic liver resection for malignancy. Thus, in the ELLH group, malignant tumors accounted for a lower proportion of the cohort. When patients faced the choice between open surgery and laparoscopic surgery, overweight patients preferred the latter because, in open surgery, they need a longer incision for good surgical exposure. With the development of minimally invasive surgery, laparoscopic liver resection has been increasingly performed for malignancy with equivalent oncological outcomes to open surgery.

Laparoscopic surgery has become the preferred method for an increasing number of patients with malignant disease as well as with benign disease not only because of improved cosmetic outcomes but also because the method results in less trauma and better recovery, so multiple differences show between two groups (Tables 1 and 4). Despite technical improvements and the worldwide expansion of laparoscopic liver resection, we maintain that the indications for the resection of benign lesions should not be widened solely because of the ability to perform major laparoscopic liver resections.

However, it is undeniable that the growing experience of the surgeon and technical advances and modifications in laparoscopic devices contributed to these results. The growing use of laparoscopic major liver resection is likely due to the technological advances and modifications in laparoscope and surgeon experience. The image magnification provided by a laparoscope considerably facilitates precise dissection of the left hepatic pedicle. The technical difficulties associated with this procedure can be overcome with systematic and standardized training to create a safe and efficacious treatment for patients.

Our results confirm that LLH is safe and feasible in experienced hands, and this improved technique simplifies the procedure of dissecting the left hepatic pedicle with reliable and safe vascular inflow control. We believe that this described technique will contribute to the development of a simplified laparoscopic major liver resection procedure. However, because a learning curve does exist, extensive experience in open liver surgery and laparoscopic left lateral sectionectomy is required before a surgeon can perform LLH. The present series has its limitations. This report was composed of a single center's experience and was unable to eliminate the interference of the learning curve to the result. We look forward to further studies in the future to support this preliminary result.

\section{Conclusions}

The improved technique described in this article is simple, safe, and novel. This procedure enables the precise dissection of the hepatic pedicle and reliable control of vascular inflow and minimizes the risk of accidental injury to the hepatic pedicle. Although laparoscopic major liver resections are complex and time-consuming procedures, we believe that LLH is likely to become a new standard of care. However, a strict training and admittance system and comprehensive patient selection criteria are necessary for the widespread use of this procedure.

\section{Acknowledgments}

The authors acknowledge the nurses and the anesthetists at the Chinese PLA (People's Liberation Army) General Hospital for their continuing contributions, without which this study could not have been performed. The authors thank Dr. Fen Yang, M.D., for her statistical assistance in this study.

\section{Disclosure Statement}

No competing financial interests exist.

\section{References}

1. Bradford LS, Boruta DM. Laparoendoscopic single-site surgery in gynecology: A review of the literature, tools, and techniques. Obstet Gynecol Surv 2013;68:295-304.

2. Rassweiler J, Rassweiler MC, Kenngott H, Frede T, Michel MS, Alken P, Clayman R. The past, present and future of minimally invasive therapy in urology: A review and speculative outlook. Minim Invasive Ther Allied Technol 2013; 22:200-209.

3. Küper MA, Eisner F, Königsrainer A, Glatzle J. Laparoscopic surgery for benign and malign diseases of the digestive system: Indications, limitations, and evidence. World J Gastroenterol 2014;20:4883-4891.

4. Buell JF, Thomas MT, Rudich S, Marvin M, Nagubandi R, Ravindra KV, Brock G, McMasters KM. Experience with more than 500 minimally invasive hepatic procedures. Ann Surg 2008;248:475-486.

5. Koffron AJ, Auffenberg G, Kung R, Abecassis M. Evaluation of 300 minimally invasive liver resections at a single institution: Less is more. Ann Surg 2007;246:385-392; discussion 92-94.

6. Yin Z, Fan X, Ye H, Yin D, Wang J. Short- and long-term outcomes after laparoscopic and open hepatectomy for hepatocellular carcinoma: A global systematic review and meta-analysis. Ann Surg Oncol 2013;20:1203-1215.

7. Dagher I, Belli G, Fantini C, Laurent A, Tayar C, Lainas P, Tranchart H, Franco D, Cherqui D. Laparoscopic hepatectomy for hepatocellular carcinoma: A European experience. J Am Coll Surg 2010;211:16-23.

8. Abu Hilal M, McPhail MJ, Zeidan B, Zeidan S, Hallam MJ, Armstrong T, Primrose JN, Pearce NW. Laparoscopic versus open left lateral hepatic sectionectomy: A comparative study. Eur J Surg Oncol 2008;34:1285-1288.

9. Azagra JS, Goergen M, Brondello S, Calmes MO, Philippe P, Schmitz B. Laparoscopic liver sectionectomy 2 and 3 (LLS 2 and 3): Towards the "gold standard." J Hepatobiliary Pancreat Surg 2009;16:422-426.

10. Dokmak S, Raut V, Aussilhou B, Ftériche FS, Farges O, Sauvanet A, Belghiti J. Laparoscopic left lateral resection is the gold standard for benign liver lesions: A case-control study. HPB (Oxford) 2014;16:183-187.

11. Pearce NW, Di Fabio F, Abu Hilal M. Laparoscopic left hepatectomy with extraparenchymal inflow control. J Am Coll Surg 2011;213:e23-e27.

12. Namgoong JM, Kim KH, Park GC, Jung DH, Song GW, Ha TY, Moon DB, Ahn CS, Hwang S, Lee SG. Comparison of laparoscopic versus open left hemihepatectomy for leftsided hepatolithiasis. Int J Med Sci 2014;11:127-133. 
13. Belli G, Gayet B, Han HS, Wakabayashi G, Kim KH, Cannon R, Gamblin T, Koffron A, Dagher I, Buell JF. International Consensus Group for Laparoscopic Liver Surgery. Laparoscopic left hemihepatectomy a consideration for acceptance as standard of care. Surg Endosc 2013;27:27212726.

14. Mirnezami R, Mirnezami AH, Chandrakumaran K, Abu Hilal M, Pearce NW, Primrose JN, Sutcliffe RP. Short- and long-term outcomes after laparoscopic and open hepatic resection: Systematic review and meta-analysis. HPB (Oxford) 2011;13:295-308.

15. Nguyen KT, Gamblin TC, Geller DA. World review of laparoscopic liver resection-2,804 patients. Ann Surg 2009;250:831-841.

16. Buell JF, Cherqui D, Geller DA, O'Rourke N, Iannitti D, Dagher I, Koffron AJ, Thomas M, Gayet B, Han HS, Wakabayashi G, Belli G, Kaneko H, Ker CG, Scatton O, Laurent A, Abdalla EK, Chaudhury P, Dutson E, Gamblin C, D’Angelica M, Nagorney D, Testa G, Labow D, Manas D, Poon RT, Nelson H, Martin R, Clary B, Pinson WC, Martinie J, Vauthey JN, Goldstein R, Roayaie S, Barlet D, Espat J, Abecassis M, Rees M, Fong Y, McMasters KM, Broelsch C, Busuttil R, Belghiti J, Strasberg S, Chari RS. World Consensus Conference on Laparoscopic Surgery. The international position on laparoscopic liver surgery: The Louisville Statement, 2008. Ann Surg 2009;250:825-830.

17. Cannon RM, Scoggins CR, Callender GG, Quillo A, McMasters KM, Martin RC. 2nd. Financial comparison of laparoscopic versus open hepatic resection using deviationbased cost modeling. Ann Surg Oncol 2013;20:2887-2892.

18. Dagher I, Gayet B, Tzanis D, Tranchart H, Fuks D, Soubrane O, Han HS, Kim KH, Cherqui D, O'Rourke N, Troisi RI, Aldrighetti L, Bjorn E, Abu Hilal M, Belli G, Kaneko H, Jarnagin WR, Lin C, Pekolj J, Buell JF, Wakabayashi G. International experience for laparoscopic major liver resection. J Hepatobiliary Pancreat Sci 2014;21:732-736.

19. Dagher I, O'Rourke N, Geller DA, Cherqui D, Belli G, Gamblin TC, Lainas P, Laurent A, Nguyen KT, Marvin MR, Thomas M, Ravindra K, Fielding G, Franco D, Buell JF. Laparoscopic major hepatectomy: An evolution in standard of care. Ann Surg 2009;250:856-860.

20. Tzanis D, Shivathirthan N, Laurent A, Abu Hilal M, Soubrane O, Kazaryan AM, Ettore GM, Van Dam RM, Lainas P, Tranchart H, Edwin B, Belli G, Campos RR, Pearce N, Gayet B, Dagher I. European experience of laparoscopic major hepatectomy. J Hepatobiliary Pancreat Sci 2013;20:120-124.

21. Kooby DA, Stockman J, Ben-Porat L, Gonen M, Jarnagin WR, Dematteo RP, Tuorto S, Wuest D, Blumgart LH, Fong $\mathrm{Y}$. Influence of transfusions on perioperative and long-term outcome in patients following hepatic resection for colo- rectal metastases. Ann Surg 2003;237:860-869; discussion 869-870.

22. Dagher I, Di Giuro G, Dubrez J, Lainas P, Smadja C, Franco D. Laparoscopic versus open right hepatectomy: A comparative study. Am J Surg 2009;198:173-177.

23. Lin NC, Nitta H, Wakabayashi G. Laparoscopic major hepatectomy: A systematic literature review and comparison of 3 techniques. Ann Surg 2013;257:205-213.

24. Abu Hilal M, Underwood T, Taylor MG, Hamdan K, Elberm H, Pearce NW. Bleeding and hemostasis in laparoscopic liver surgery. Surg Endosc 2010;24:572-577.

25. Han HS, Cho JY, Yoon YS. Techniques for performing laparoscopic liver resection in various hepatic locations. J Hepatobiliary Pancreat Surg 2009;16:427-432.

26. Di Giuro G, Lainas P, Franco D, Dagher I. Laparoscopic left hepatectomy with prior vascular control. Surg Endosc 2010;24:697-699.

27. Cho A, Yamamoto H, Kainuma O, Souda H, Ikeda A, Takiguchi N, Nagata M. Safe and feasible extrahepatic Glissonean access in laparoscopic anatomical liver resection. Surg Endosc 2011;25:1333-1336.

28. Rotellar F, Pardo F, Benito A, Martí-Cruchaga P, Zozaya G, Pedano N. A novel extra-glissonian approach for totally laparoscopic left hepatectomy. Surg Endosc 2012;26:2617-2622.

29. Topal B, Aerts R, Penninckx F. Laparoscopic intrahepatic Glissonian approach for right hepatectomy is safe, simple, and reproducible. Surg Endosc 2007;21:2111.

30. Machado MA, Makdissi FF, Surjan RC, Herman P, Teixeira AR, C Machado MC. Laparoscopic resection of left liver segments using the intrahepatic Glissonian approach. Surg Endosc 2009;23:2615-2619.

31. Figueras J, Lopez-Ben S, Lladó L, Rafecas A, Torras J, Ramos E, Fabregat J, Jaurrieta E. Hilar dissection versus the "glissonean" approach and stapling of the pedicle for major hepatectomies: A prospective, randomized trial. Ann Surg 2003;238:111-119.

Address correspondence to: Rong Liu, MD Department of Hepatobiliary and Pancreatic Surgical Oncology Chinese PLA General Hospital 28 Fuxing Road Haidian District Beijing 100853

China

E-mail: dr_liurong@126.com 